\title{
Compartmental models of nitrogen cycling in tropical and temperate marine environments
}

\author{
Julie LaRoche ${ }^{1} \&$ W. G. Harrison ${ }^{2}$ \\ ${ }^{1}$ Department of Biology, Dalhousie University, Halifax, Nova Scotia B3H 4J1, Canada \\ ${ }^{2}$ Marine Ecology Laboratory, Bedford Institute of Oceanography, Department of Fisheries and Oceans, Dartmouth, Nova Scotia \\ B2Y 4A2, Canada
}

\begin{abstract}
Time-course measurements of ${ }^{15} \mathrm{~N}$ tracer kinetics in particulate organic and in $\mathrm{NH}_{4}^{+}$pools from tropical and temperate regions were used to test several compartmental models describing the exchange of ${ }^{15} \mathrm{~N}$ tracer in microplankton communities. Several lines of evidence suggested the involvement of a third, dissolved pool, arbitrarily labelled dissolved organic nitrogen (DON). Although the kinetic patterns of tracer movement were different between the tropical stations and the temperate one, the same 3-compartmental model in which PON and DON can exchange material only through the intermediate of $\mathrm{NH}_{4}^{+}$gave the best fit. Only the transfer coefficients were modified. Results show that compartmental analysis is useful for the estimation of compartmental transfer rates and for testing the assumptions implicit in any given model.
\end{abstract}

\section{INTRODUCTION}

Compartmental models have been applied extensively in the evaluation of tracer movements through biological systems, especially in the fields of physiology and medicine (Jacquez 1972). A well-developed theory of compartmental analysis facilitates considerably the interpretation of observed tracer kinetics (Jacquez 1972, Anderson 1983)

Tracer techniques to measure carbon, phosphorus and nitrogen uptake by marine plankton are well established (e.g. Steeman-Nielsen 1952, Rice 1953, Dugdale \& Goering 1967). Most experiments are generally designed to measure only nutrient uptake or nutrient incorporation into particulate matter; little study has been devoted to other possible pathways of tracer exchange in microplankton. Tracer studies of phosphorus exchange in plankton (e.g. Rigler 1956) are exceptional, however, and have followed the conventional compartmental analysis approach (Sheppard 1962). Past studies have identified various pathways of phosphorus exchange in the marine and freshwater plankton communities (Rice 1953, Rigler 1956, Lean 1973, Taft et al. 1975, Currie \& Kalff 1984a, b, Smith et al. 1985). Recently, more detailed models of carbon exchange have also been investigated ((Wiebe \& Smith 1977, Dring \& Jewson 1982, Smith 1982, Smith \& Platt 1984). Although one expects that models describing carbon and phosphorus cycling would differ because of differences in elemental metabolism, there is growing evidence that cycling through a dissolved organic pool may be a common and important pathway for both elements (Lean 1973, Wiebe \& Smith 1977, Smith et al. 1985).

Models of ${ }^{15} \mathrm{~N}$ tracer exchange, on the other hand, have not been studied systematically, partly because the time-course data necessary to evaluate various models are difficult to collect. Dugdale \& Goering (1967) suggested a simple model describing the incorporation of ${ }^{15} \mathrm{~N}$ into particulate matter. In recent years, however, it has become evident that various assumptions in this early model are not valid. For example, it is now fairly well documented that isotope-dilution of $\mathrm{NH}_{4}^{+}$, assumed by Dugdale \& Goering to be insignificant, is common in in vitro tracer experiments (Harrison 1978, Caperon et al. 1979, Glibert et al. 1982, Paasche \& Kristiansen 1982, LaRoche 1983). Blackburn (1979) and Caperon et al. (1979) proposed a model (referred to as the 'Blackburn-Caperon model' below) which described the changes in the concentration and isotope ratio of the $\mathrm{NH}_{4}^{+}$pool.

Glibert et al. (1982) noted that tracer conservation was not observed in field experiments in which 2 nitrogen pools were measured, i.e. not all of the tracer leaving the $\mathrm{NH}_{4}^{+}$pool was recovered in the particulates (see also Harrison 1983). Laws (1984) also discussed 
this apparent missing tracer, suggesting that a third compartment (e.g. dissolved organic nitrogen) may play a much more important role in microplankton nitrogen cycling than earlier believed.

In this paper, several exchange models are evaluated in terms of compartmental analysis. This is made possible by using time-course data on the movements of ${ }^{15} \mathrm{~N}$ between the ammonium and particulate nitrogen pools from natural microplankton populations of coastal and oceanic waters. These data are used to test various models including those for carbon and phosphorus exchange (Smith \& Platt 1984, Smith et al. 1985).

\section{MODELS OF NITROGEN CYCLING}

\section{Dugdale \& Goering model}

Dugdale \& Goering (1967) were the first to use ${ }^{15} \mathrm{~N}$ as a tracer for nitrogen cycling studies in the marine environment. Their conceptual model of the planktonic nitrogen cycle is complex (Fig. 1) and can be described by a set of 5 simultaneous differential equations. However, the authors greatly simplified these equations to calculate $\mathrm{NH}_{4}^{+}$uptake rates by using the following assumptions. (1) Quasi-steady-state conditions were assumed. This implies that the total nitrogen input into the system is equal to the total output (i.e. $\rho_{10}+\rho_{02}=$ $\left.\rho_{40}+\rho_{15}\right)$ and therefore that the pathways of $\mathrm{NH}_{4}^{+}$ cycling would be equal $\left(\rho_{21}=\rho_{32}=\rho_{13}\right)$. (2) Oxidation of $\mathrm{NH}_{4}^{+}$to $\mathrm{NO}_{3}$ as well as transformations involving dissolved organic nitrogen were considered negligible. Although the authors recognized that substrate isotope dilution' could occur, this was considered to be insignificant and was therefore omitted in the derivation of the equations, i.e. the tracer proportion of the substrate (at \% ${ }^{15} \mathrm{~N}$ in the $\mathrm{NH}_{4}^{+}$) was assumed to be constant.

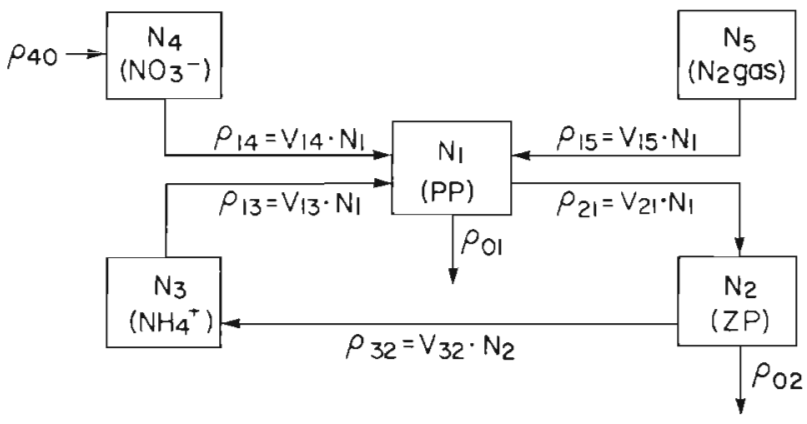

Fig. 1. Dugdale \& Goering's model of nitrogen cycling. PP: phytoplankton pool; ZP: zooplankton pool pij: transfer rates, in $\mu \mathrm{g} \mathrm{l}^{-1} \mathrm{t}^{-1}$, of material from the $\mathrm{j}^{\text {th }}$ pool transferred to the $\mathrm{i}^{\text {th }}$ pool. $V_{13}$ : transfer rate constants (in $t^{-1}$ ). $\mathrm{N}$ : biomass in com-

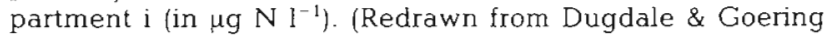
1967)
The following equation was used to describe the change in the at $\%{ }^{15} \mathrm{~N}$ in the PON pool with time:

$$
\frac{d a_{1}}{d t}=V_{13}\left(a_{3}-a_{1}\right)
$$

where $\mathrm{a}_{1}$ and $\mathrm{a}_{3}=\mathrm{at} \%{ }^{15} \mathrm{~N}$ in the PON and the $\mathrm{NH}_{4}^{+}$ pools respectively; $V_{13}=$ a transfer coefficient (with dimensions of $\mathrm{T}^{-1}$ ). In this model (presented schematically in Fig. 2a), it is assumed that $V_{13}$ is independent of the size of the $\mathrm{NH}_{4}^{+}$pool but is proportional to the PON pool size. This formulation of nitrogen uptake is identi$\mathrm{cal}$ to the 'traditional' model for the ${ }^{14} \mathrm{C}$ uptake rate calculation in primary productivity studies (cf. Smith 1982, Smith \& Platt 1984).

\section{Blackburn-Caperon model}

The model by Blackburn (1979) and Caperon et al. (1979) was formulated to follow the kinetics of ${ }^{15} \mathrm{~N}$ in the $\mathrm{NH}_{4}^{+}$pool. In the simplest case, it is possible to represent the environment as a single homogeneous pool (Fig. 2b). The following assumptions were associated with the original Blackburn-Caperon model: (1) uptake and regeneration rates are constant during the incubations (dimensions of $\mathrm{MT}^{-1}$ ); (2) there is no recycling of the ${ }^{15} \mathrm{~N}$ during the incubation period; and (3) uptake and regeneration rates are independent of $\mathrm{NH}_{4}^{+}$ concentration.

It is worth considering the simplest 2-compartment model, implicit in the work of several authors (Garside \& Glibert 1984, Laws 1984, 1985). The original 1-compartment model described by Blackburn (1979) and

(a)

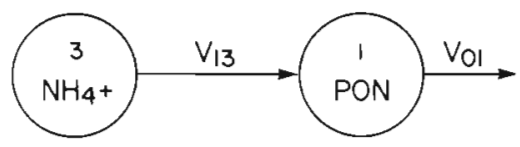

(b)

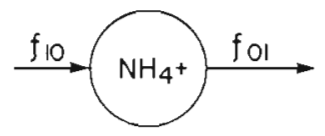

(c)

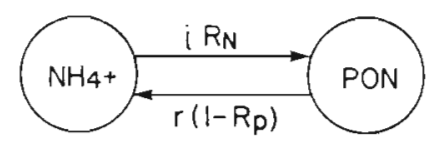

Fig. 2. Compartmental models used in ammonium cycling studies. (a) Model used by Dugdale \& Goering (1967) to calculate $\mathrm{NH}_{4}^{+}$uptake by particulate nitrogen. (b) Compartmental model used to describe Blackburn (1979) and Caperon et al. (1979) model of $\mathrm{NH}_{4}^{+}$regeneration. (c) Modified Blackburn-Caperon model. $\mathrm{R}_{\mathrm{N}}$ and $\mathrm{R}_{\mathrm{p}}$ : at $\%{ }^{15} \mathrm{~N}$ in the $\mathrm{NH}_{4}$ and the PON pool respectively; $\mathrm{i}$ and $\mathrm{r}$ : uptake and regeneration rates (in units of umole $1^{-1} \mathrm{~h}^{-1}$ ) 
Caperon et al. (1979) (Fig. 2b) then becomes the 2compartment model presented in Fig. 2c and hereafter called the 'modified Blackburn-Caperon model'. This closed 2-compartment model requires mass conservation of the added tracer. It is used, in general, as a nonsteady-state model and can be described by the following equations for mass balance:

$$
\begin{aligned}
& P_{\text {total }}=P_{n}(t)+P_{p}(t) \\
& P_{n}(t)=P_{n}(0)+(r-i) t \\
& P_{p}(t)=P_{p}(0)-(r-i) t
\end{aligned}
$$

where $P_{\text {total }}=$ total amount of nitrogen during the incubation (a constant); $P_{n}(t)$ and $P_{p}(t)=$ concentrations of nitrogen at time $t$ in the $\mathrm{NH}_{4}^{+}$pool and in the particulate pool respectively; $\mathrm{P}_{n}(0)$ and $\mathrm{P}_{\mathrm{p}}(0)=$ initial pool sizes; $r\left(\right.$ or $\left.f_{10}\right)=$ regeneration rate (dimensions of $\left.\mathrm{MT}^{-1}\right)$; and $\mathrm{i}\left(\right.$ or $\left.\mathrm{f}_{01}\right)=$ uptake rate $\left(\right.$ dimensions of $\left.\mathrm{MT}^{-1}\right)$. The change in the isotopic ratio of the $\mathrm{NH}_{4}^{+}$pool with time is described by the following equation:

$$
R_{n}(t)=R_{n}(0) /\left(\frac{P_{n}(0)+(r-i) t}{P_{n}(0)}\right)^{r /(r-i)}
$$

where $R_{n}(t)$ and $R_{n}(0)=a t \%{ }^{15} \mathrm{~N}$ at time $t$ and at time zero respectively in the $\mathrm{NH}_{4}^{+}$pool. An equation for the change in the at $\%{ }^{15} \mathrm{~N}$ in the particulate nitrogen can
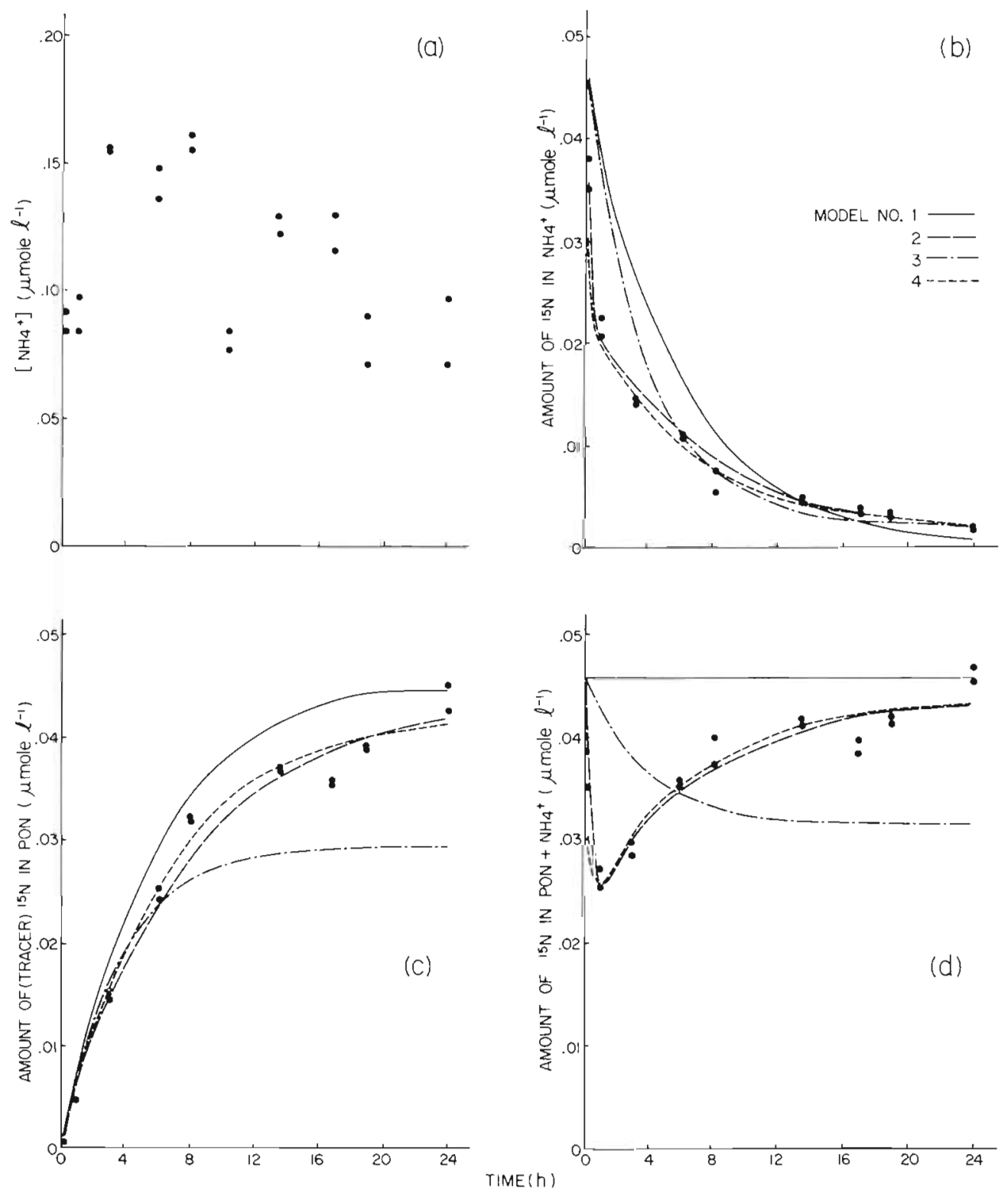

Fig. 3. Time-course data for the tropical offshore station OS1. (a) $\mathrm{NH}_{4}^{+}$concentrations; (b) ${ }^{15} \mathrm{~N}$ in $\mathrm{NH}_{4}^{+}$; (c) ${ }^{15} \mathrm{~N}$ in $\mathrm{PON}$; and (d) ${ }^{15} \mathrm{~N}$ in both the $\mathrm{NH}_{4}^{+}$and PON pools. Lines indicate the best fits of Models 1, 2a, 3a and 4 of Fig. 8 
be easily derived using the mass balance constraint. At any time, the total amount of tracer $\left(X_{\text {total }}\right)$ is

$$
\mathrm{X}_{\text {total }}=\mathrm{X}_{\mathrm{p}}(\mathrm{t})+\mathrm{X}_{\mathrm{n}}(\mathrm{t})
$$

where $X_{p}(t)$ and $X_{n}(t)=$ amounts of tracer in the PON and in the $\mathrm{NH}_{4}^{+}$pools, respectively. As in the derivation of Dugdale \& Goering's (1967) model, the amount of tracer in any pool is described as:

$$
X_{1}(t)=R_{i}(t) \cdot P_{j}(t)
$$

So, solving for the amount of tracer in the particulate pool:

$$
\begin{gathered}
X_{p}(t)=X_{\text {total }}-R_{n}(t) \cdot P_{n}(t) \\
R_{p}(t) \cdot P_{p}(t)=X_{\text {total }}-R_{n}(t) \cdot P_{n}(t)
\end{gathered}
$$

where $R_{p}(t)=a t \%{ }^{15} \mathrm{~N}$ in the PON pool.
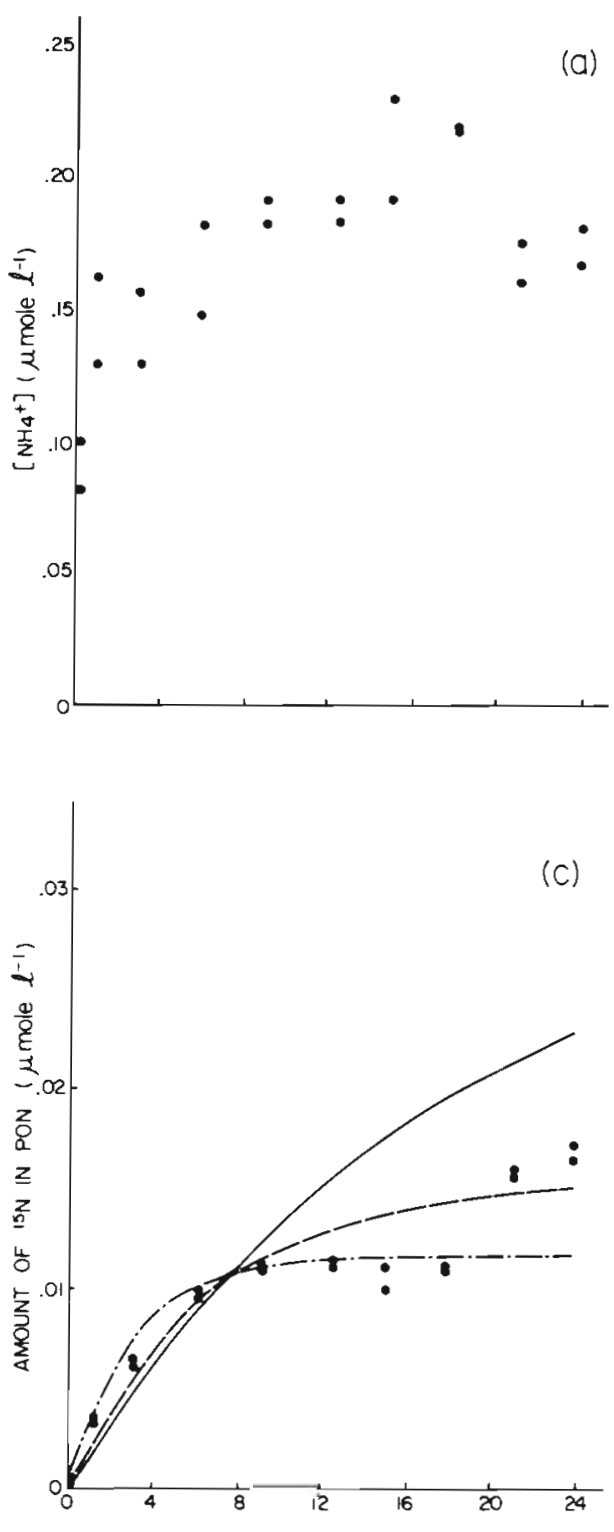

(C)

Fig. 4. Time course data of the tropical offshore station OS2. Legend as in Fig. 3
Since the total amount of tracer is initially in the $\mathrm{NH}_{4}^{+}$ pool:

$$
\begin{aligned}
& R_{p}(t) \cdot P_{p}(t)=R_{n}(0) \cdot P_{n}(0)-R_{n}(t) \cdot P_{n}(t) \\
& R_{p}(t)=\frac{1}{P_{p}(t)}\left(R_{n}(0) \cdot P_{n}(0)-R_{n}(t) \cdot P_{n}(t)\right)
\end{aligned}
$$

\section{METHODS}

Experimental procedures. The analyses described in this paper are based on data from 4 time-course experiments. Three of these experiments were carried out in water off the coast of Oahu, Hawaii, during the fall of 1982 as part of the PRPOOS program (Eppley 1982, Harrison \& Harris 1986). Two of these experiments were performed in offshore waters, (OS1 and OS2) and
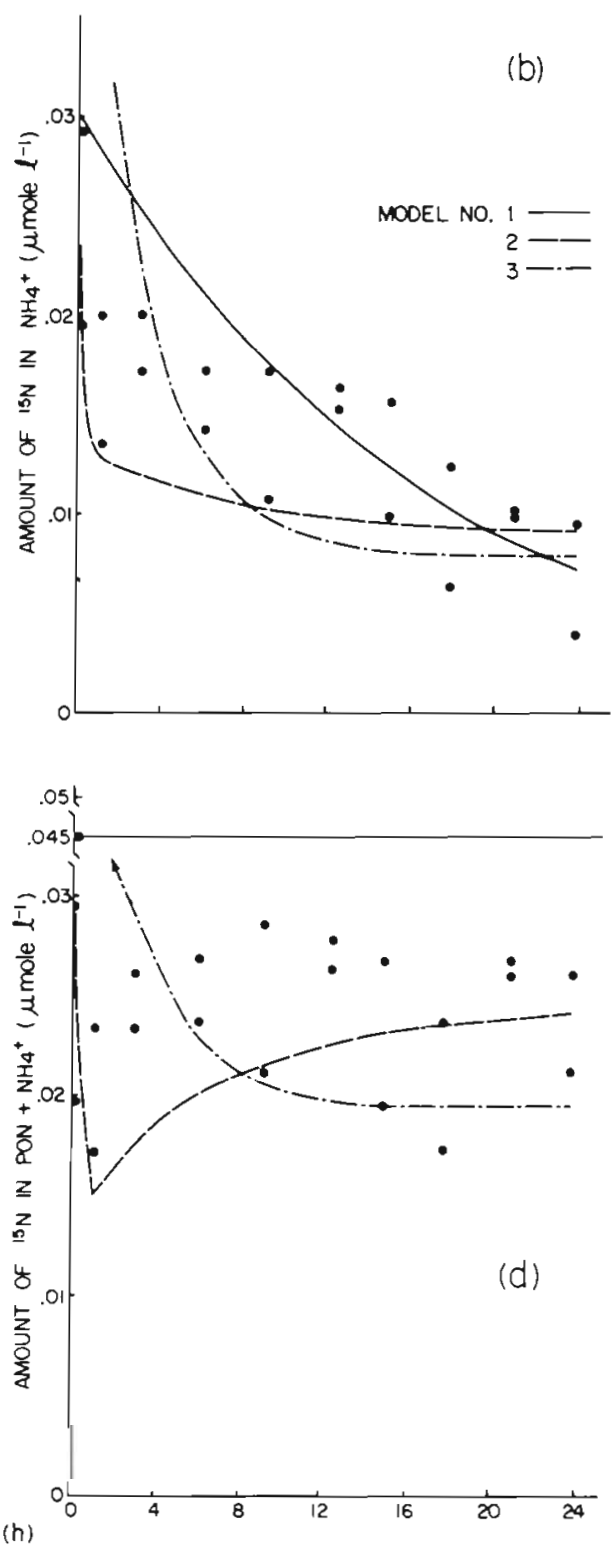
the third was in a eutrophic embayment, Kaneohe Bay (KB1). Details of the sampling and experimental procedures are described elsewhere (Smith et al. 1985, Laws et al. 1984, 1985, Harrison \& Harris 1986). The fourth experiment was carried out in temperate coastal waters, Bedford Basin, Nova Scotia, Canada (La Roche 1981). Polycarbonate bottles of 41 , specially treated to minimize trace metal contamination (Fitzwater et al. 1982), were used in the Hawaii experiments. Acidwashed 1 l borosilicate glass bottles were used in Bedford Basin. Data sets consisted of time-courses of $\mathrm{NH}_{4}^{+}$concentrations, and of ${ }^{15} \mathrm{~N}$ content in the $\mathrm{NH}_{4}^{+}$and PON pools. PON concentrations were measured initially and on most occasions, at the end of experiments.
Compartmental analysis. The modified BlackburnCaperon model (Eqns 3, 5 \& 11) was fitted to the data for each experiment. The parameter values $i$ and $r$ which gave the best fit to the data were obtained using non-linear least-squares regression procedures (SPSS: Nie et al. 1975). Fitting procedures of all the other postulated models presented were essentially the same except that either numerical solutions (simulations) or analytical solutions were used to calculate the leastsquares parameter estimates (SAAM: Berman \& Weiss 1978).

All other models analysed follow the rules of compartmental analysis (Berman \& Schoenfeld 1956, Sheppard 1962, Jacquez 1972) and are among the
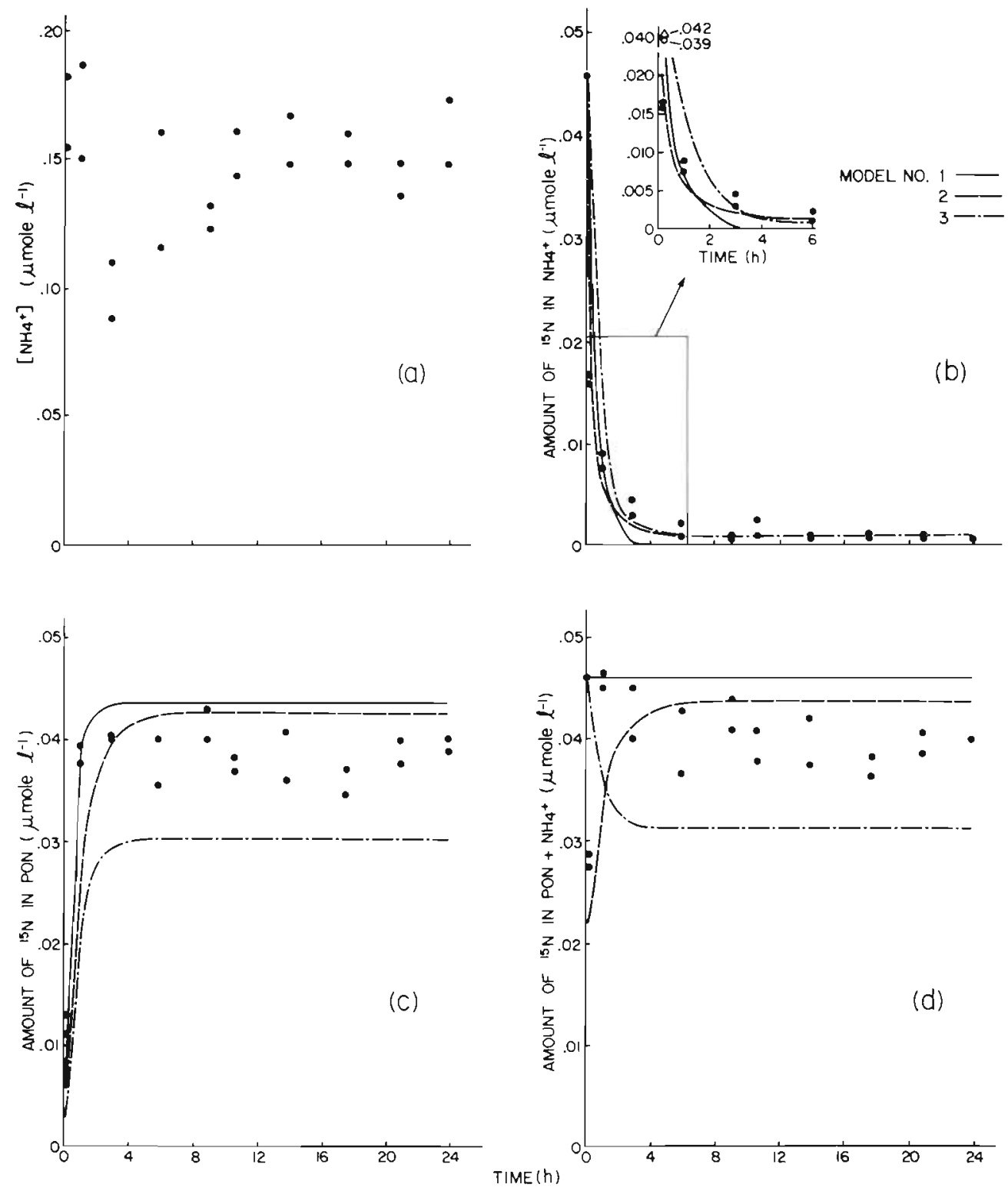

Fig. 5. Time course data of the tropical inshore station KB1. Legend as in Fig. 3 
simplest form of compartmental models, i.e. 1st order kinetic models. The 2 basic assumptions made with this type of compartmental model are: (1) the transfer coefficients $\left(\mathrm{T}^{-1}\right)$ are constant and thus independent of pool size $_{i}(2)$ there is no discrimination between isotopes, i.e. the net transfer of isotope occurs according to its abundance in each pool, thus isotope recycling will occur. Recycling of tracer isotope to the pool where it was initially introduced depends on the rate at which the tracer is transferred to other pools. Isotope recycling depends on how heavily labelled other pools will be and should therefore be small during the early stage of a time-course experiment and increase with time.

\section{RESULTS}

The results of the 4 time-course experiments are presented in Fig. 3 to 6 . Significant changes in $\mathrm{NH}_{4}^{+}$ concentration occurred in 2 experiments. A net decrease was observed in Bedford Basin (Fig. 6), and a slight increase was detected for experiment OS2. There were no significant trends in the $\mathrm{NH}_{4}^{+}$time-courses for Experiments OS1 and KB1 (Fig. 3a \& 5a). In all cases, however, it appeared that the particulate nitrogen concentration did not change appreciably during the course of the Hawaii experiments (Renger 1983).

Changes in the at $\%{ }^{15} \mathrm{~N}$ in the $\mathrm{NH}_{4}^{+}$(e.g. Fig. 7a)
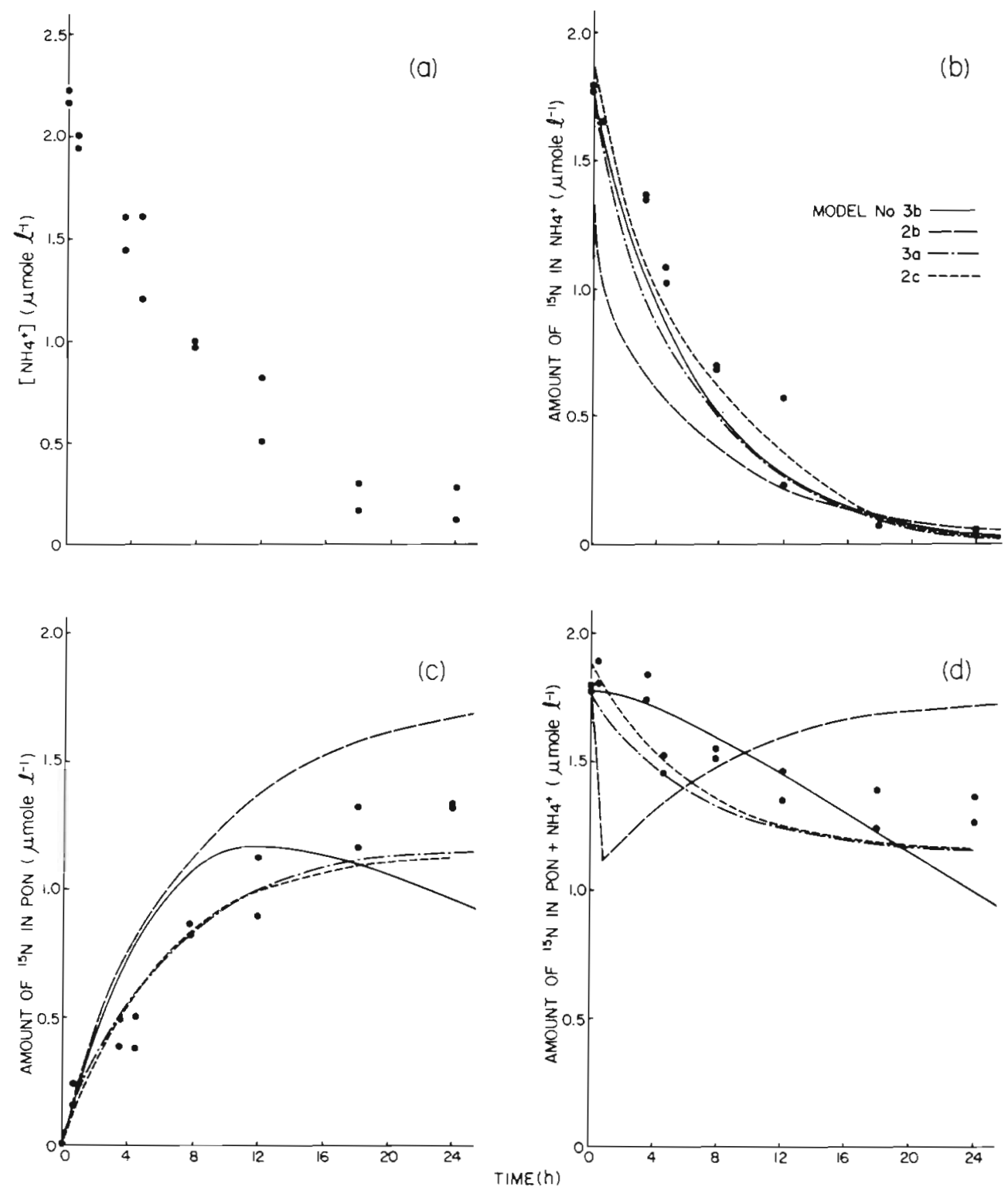

Fig. 6. Time course data of the temperate station, Bedford Basin (BB). Legend as in Fig. 3, except that the models fitted were 3b, $2 b, 3 a$ and $2 c$ of Fig. 8 

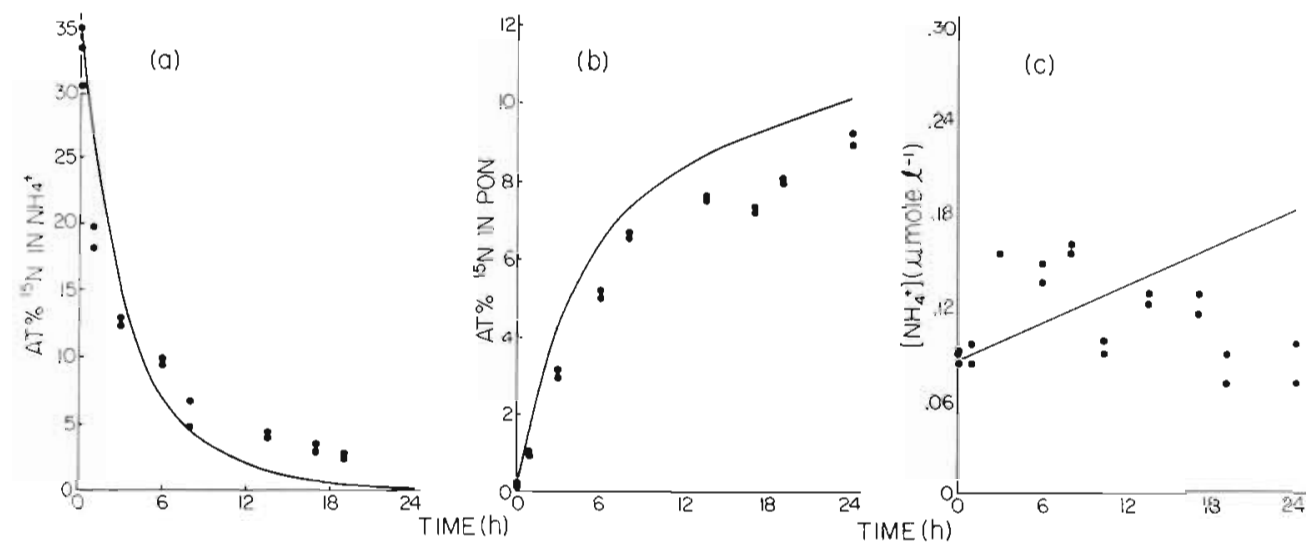

Fig. 7. Fit of the Blackburn-Caperon model (solid line) to the time-course from Stn OS1. (a) Shows the fit of the model to the at $\%$

${ }^{15} \mathrm{~N}$ in the $\mathrm{NH}_{4}^{+}$pool; (b) shows the fit to the at ${ }^{15} \mathrm{~N}$ present in the PON, and (c) shows the model fit to the $\mathrm{NH}_{4}^{+}$pool

indicated that the assumption of constant substrate specific activity, necessary to the Dugdale \& Goering model, was not appropriate for the experimental data presented here (see also Harrison \& Harris 1986). No attempt was made here to fit their model since it was clearly invalidated by the experimental observations; Harrison \& Harris (1986) have dealt with this.

Attempts to fit the modified Blackburn-Caperon model to the experimental data often resulted in large

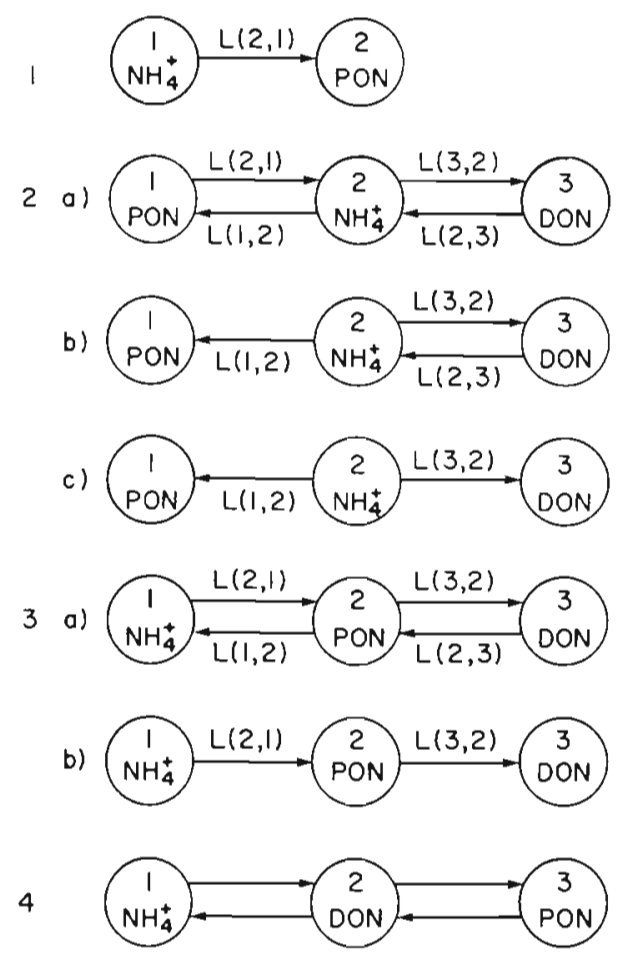

Fig. 8. Diagram illustrating the models fitted (tested) to the 4 experiments used in this paper. $L(i, j)$ represent the fractional transfer rate of material (in units of $h^{-1}$ ) from the $j^{\text {th }}$ to the $i^{\text {th }}$ pool initial residual variance (i.e. variance after the fit of the initial parameter estimates], indicating an unacceptable lack of fit of the model to the data. Parameter estimates for the modified Blackburn-Caperon model were obtained only for OS1 and OS2 time-course data, and the best case of this analysis, obtained with Experiment OS1, is presented in Fig. 7. Although parameter estimates could be obtained for this data set, the systematic lack of fit of the model is readily noticeable. For example, the model overestimates the at $\%{ }^{15} \mathrm{~N}$ in PON throughout the time course; the at\% ${ }^{15} \mathrm{~N}$ in $\mathrm{NH}_{4}^{-}$is initially overestimated but becomes underestimated towards the end of the incubation. Likewise, the model predicted a doubling in the $\mathrm{NH}_{4}^{+}$concentration that was not observed in the data. Other 2-compartment models which assume steady-state (for example, Model 1, Fig. 8) also gave a similar systematic lack of fit to the data.

All closed 2-compartment models, including the modified Blackburn-Caperon version, require conservation of the tracer. Fig. $3 d$ to $6 d$ show that this was not the case for 3 of the 4 experiments. Moreover, in some experiments, definite trends were observed in the total ${ }^{15} \mathrm{~N}$ tracer. In OS1, there was initially (within the first hour of incubation) a rapid decrease of ${ }^{15} \mathrm{~N}$ followed by an asymptotic increase, approaching the amount of tracer initially added. Variable tracer recovery was also observed in the KB1 and OS2 experiments although trends were not as obvious. A noticeable decrease in the recovery of tracer was also evident in the Bedford Basin experiment (Fig. 6d). It would therefore appear that a closed 2-compartment model is inappropriate to explain the experimental observations presented here.

It is possible to identify the number of compartments needed for a particular data set by fitting a sum of exponentials model to the data (Berman \& Schoenfeld 1956, Anderson 1983). Several exponential functions, including between 2 and 4 terms, were fitted. In gen- 
eral, the best description of the data was obtained with a sum of 3 exponentials model. For example, the sum of exponentials model that best fit the data from OS1 was:

$$
\begin{gathered}
Y_{\mathrm{NH}_{4}^{+}}(\mathrm{t})=1.5+17.4 \mathrm{e}^{-0.147 t}+15.9 \mathrm{e}^{-1.88 \mathrm{t}} \\
\mathrm{Y}_{\mathrm{PON}(\mathrm{t})}=8.78-8.78 \mathrm{e}^{-0.148 \mathrm{t}}
\end{gathered}
$$

where $\mathrm{Y}_{\mathrm{NH}_{4}^{+}}(\mathrm{t})$ and $\mathrm{Y}_{\mathrm{PON}(\mathrm{t})}=$ predicted values of at $\%{ }^{15} \mathrm{~N}$ in $\mathrm{NH}_{4}^{+}$and in PON time-courses, respectively. Empirical models with 3 exponential terms fitted all of the time-courses well, suggesting that a 3-compartment model may be most appropriate for the data described here.

A number of 3-compartment models (Fig. 8, Models 2,3 and 4) were tested; the residual sum of squares for each model is presented in Table 1 . The parameters for Model 2 (Model 2a for Hawaii experiments; Model 2c for Bedford Basin experiments) which gave the minimum residual sum of squares are listed in Table 2. In order to assess the effect of variable $\mathrm{NH}_{4}^{+}$pool size, observed in 2 of the experiments, several models with time-varying coefficients (i.e. 2nd order kinetic, with parameter dependence on either $\mathrm{NH}_{4}^{+}$or PON pool size) were fitted to the experimental data. Overall, the models with constant transfer coefficients (1st order kinetic) gave best results for the Hawaii experiment. The Bedford Basin experiment on the other hand, was described slightly better (Table 1) by Model 2c when one of the transfer coefficients (L[1,2]:transfer of tracer from $\mathrm{NH}_{4}^{+}$to $\mathrm{PON}$ ) was forced to be dependent on the PON pool size (Table 1, Model 2C ${ }^{\circ}$ ). This second order kinetic model (Fig. 8, Model 2c) assumed that the change in PON was inversely proportional to the $\mathrm{NH}_{4}^{+}$ disappearance. This implied that there should have been a $20 \%$ increase in PON pool size during the incubation. No such increase was observed based on initial and end-point PON measurements. It was therefore difficult to justify the use of a 2nd order kinetic model in spite of the decrease in the residual sum of squares. These analyses indicate that the dependence of transfer coefficients on pool size may not be very important in $\mathrm{NH}_{4}^{+}$cycling models and that 1st order kinetic models are adequate (Smith 1974). When 2 models give equally good fits, the simpler one (i.e. transfer coefficients independent of pool size) is usually preferred (Smith et al. 1985, Jacquez 1972, Riggs 1972).

Model 3 (Fig. 8), a model allowing the exchange of

Table 1. Residual sum of squares for the models tested (fitted) to the experimental data sets. This table summarizes the residual sum of squares for the $\mathrm{NH}_{4}^{+}$and PON pools of the tropical offshore stations (OS1 and OS2), the tropical inshore station (KB1) and the Bedford Basin (BB). (Refer to Fig. 8 and 'Results' for model descriptions). The $\mathrm{NH}_{4}^{+}$assimilation constant (L[1, 2]) in Model $2 \mathrm{C}^{\circ}$

\begin{tabular}{|c|c|c|c|c|c|c|c|c|}
\hline \multirow[b]{3}{*}{ Models } & \multicolumn{8}{|c|}{ Station } \\
\hline & \multicolumn{2}{|c|}{ OS1 } & \multicolumn{2}{|c|}{ OS2 } & \multicolumn{2}{|c|}{ KB1 } & \multicolumn{2}{|c|}{$\mathrm{BB}$} \\
\hline & $\mathrm{NH}_{4}^{+}$ & PON & $\mathrm{NH}_{4}^{+}$ & PON & $\mathrm{NH}_{4}^{+}$ & PON & $\mathrm{NH}_{4}^{+}$ & PON \\
\hline 1 & $0.38 \times 10^{-4}$ & $0.65 \times 10^{-5}$ & $0.16 \times 10^{-4}$ & $0.18 \times 10^{-4}$ & $0.96 \times 10^{-4}$ & $0.52 \times 10^{-5}$ & - & - \\
\hline $2 a$ & $0.33 \times 10^{-5}$ & $0.25 \times 10^{-5}$ & $0.29 \times 10^{-5}$ & $0.13 \times 10^{-4}$ & $0.43 \times 10^{-5}$ & $0.87 \times 10^{-5}$ & - & - \\
\hline$b$ & - & - & - & - & - & - & $0.84 \times 10^{-1}$ & $0.86 \times 10^{-1}$ \\
\hline c & - & - & - & - & - & - & $0.3 \times 10^{-1}$ & $0.27 \times 10^{-1}$ \\
\hline$c^{\circ}$ & & & & & & & $0.29 \times 10^{-1}$ & $0.27 \times 10^{-1}$ \\
\hline $3 a$ & $0.18 \times 10^{-4}$ & $0.11 \times 10^{-4}$ & $0.3 \times 10^{-4}$ & $0.43 \times 10^{-5}$ & $0.39 \times 10^{-4}$ & $0.11 \times 10^{-4}$ & $0.33 \times 10^{-1}$ & $0.26 \times 10^{-1}$ \\
\hline $\mathbf{b}$ & & - & - & - & - & - & $0.39 \times 10^{-1}$ & $0.93 \times 10^{-1}$ \\
\hline 4 & $0.32 \times 10^{-5}$ & $0.91 \times 10^{-5}$ & - & - & - & - & - & - \\
\hline
\end{tabular}
(Bedford Basin) was forced by the function $\mathrm{G} 1=8.97-1.9$ exp $\left(-0.10368^{\circ} \mathrm{T}\right)$

Table 2. Parameter values for fit of Model 2 (Fig. 8). L(i,j) represent the fractional transfer coefficient (units of $\mathrm{h}^{-1}$ ) for the transfer of material from the $j^{\text {th }}$ pool to the $\mathrm{i}^{\text {th }}$ pool. The transfer coefficients for Stns OS1, OS2 and KB1 are from the fit of Model 2 to the data. The transfer coefficients for the Bedford Basin Station are from Model $2 \mathrm{c}$ and $2 \mathrm{C}^{\circ}$. . Represents the assimilation rate constant forced to be dependent on the PON pool size by the function $G 1=8.67-1.9 \exp \left(-0.10368^{\circ} \mathrm{T}\right)$

\begin{tabular}{|ccccc}
\hline & & \multicolumn{2}{c}{ Parameters $\left(\mathrm{h}^{-1}\right)$} & $\mathrm{L}(2,3)$ \\
Station & $\mathrm{L}(1,2)$ & $\mathrm{L}(2,1)$ & $\mathrm{L}(3,2)$ \\
\hline OS1 & $0.24 \pm 0.02$ & $0.005 \pm 0.002$ & $3.3 \pm 0.4$ & $3.3 \pm 0.4$ \\
OS2 & $0.16 \pm 0.02$ & $0.09 \pm 0.02$ & $4.3 \pm 0.9$ & $10.0 \pm 2.0$ \\
KB1 & $2.6 \pm 0.4$ & $0.06 \pm 0.01$ & $5.8 \pm 2.6$ & $12.0 \pm 3.0$ \\
BB & $0.100 \pm 0.005$ & - & - & $0.066 \pm 0.006$ \\
& $0.0129 \pm 0.0006$ & - & - & $0.061 \pm 0.005$ \\
\hline
\end{tabular}


tracer between $\mathrm{NH}_{4}^{+}$pool and 'DON' pool via the PON pool only, has been applied successfully in some studies of carbon (Wiebe \& Smith 1977) and phosphorus cycling (Smith et al. 1985). However, other workers (Dring \& Jewson 1982, Smith \& Platt 1984) have found this model to be unsatisfactory for carbon. Model 4 (Fig. 8) was tested because of its successful application in phosphorus studies (Lean 1973, Currie \& Kalff $1984 \mathrm{a}, \mathrm{b}$ ). Model 2 or a slight variation of it (Model 2c) gave the best fit to all the data sets. The exchange mechanism described by Model 2 predicts direct interactions between the $\mathrm{NH}_{4}^{+}$pool and a dissolved organic nitrogen' pool. In the Hawaii experiments, the dynamics of the ${ }^{15} \mathrm{~N}$ tracer were best explained by allowing a rapid exchange of tracer between the $\mathrm{NH}_{4}^{+}$ and the DON pool, accounting for the apparent loss and subsequent recovery of tracer observed (Fig. 3d, $4 d, 5 d$ ). The particulate pool (collected on glass fiber filters) apparently interacted more slowly with the $\mathrm{NH}_{4}^{+}$ pool, but, in the long term, accumulated the largest quantity of tracer.

Pool sizes can be calculated from the estimated transfer coefficients. Table 3 is a comparison of the ratios of measured and predicted PON to $\mathrm{NH}_{4}^{+}$pool sizes. Only at Station OS2 did predicted ratios correspond closely with the measured ones. At OS1 and KB1, the predicted ratios are 12 and 2.5 times greater than the measured ones, respectively. This may have been due to discrepancies among analytical techniques leading to over- or underestimates of pool sizes. The preferred models (Model 2a for the Hawaii experiments and Model 2c for the Bedford Basin experiment) were chosen on the basis of least-squares best fit (Table 1). However, as mentioned by Smith et al. (1985), one must be cautious in this approach since this choice does not prove that the nitrogen exchange pathways represented by the model are operating in nature. The model simply represents a possible description off compartments and exchange pathways which can reproduce the experimental observations well.

\section{DISCUSSION}

Until a few years ago, the conventional analysis of ${ }^{15} \mathrm{~N}$ tracer experiments used single endpoint measurements to obtain transfer rates (Harrison 1983). Two different models, the Dugdale \& Goering (1967) and the Blackburn-Caperon models (Blackburn 1979, Caperon et al. 1979), were used to calculate nitrogen uptake and regeneration rates, respectively. The Dugdale \& Goering (1967) model describes the at $\%{ }^{15} \mathrm{~N}$ in the PON pool and the Blackburn-Caperon model describes the at $\%{ }^{15} \mathrm{~N}$ in the $\mathrm{NH}_{4}^{+}$pool. The models are both mathematically complete (i.e. they have as many equations as variables and can be solved, providing that initial and single end point measurements of at $\%$ ${ }^{15} \mathrm{~N}$ in the particulate and dissolved inorganic pools are available). In the experiments described here, simultaneous detailed time-courses of change in ${ }^{15} \mathrm{~N}$ isotope in both $\mathrm{PON}$ and $\mathrm{NH}_{4}^{+}$pool were available. This type of data can be used for the calculation of uptake and regeneration rate using the conventional models, but they are also valuable in investigating cycling mechanisms. In this study, we were seeking the simplest model that could simultaneously predict the change in the amount of tracer in the PON and $\mathrm{NH}_{4}^{+}$pool during the course of the experiments. The 'traditional' models may be useful for estimating uptake and regeneration rates when only single endpoint measurements are available. On the other hand, it is clear that these models do not adequately describe the mechanisms of exchange between the PON and the $\mathrm{NH}_{4}^{+}$pools when time course data are considered and are under the constraints of the assumptions outlined above. A systematic lack of fit of all closed 2-compartment models tested was apparent. The models' prediction of at $\%{ }^{15} \mathrm{~N}$ in PON were too high while the predictions were too low for $\mathrm{NH}_{4}^{+}$, especially towards the end of the incubations. Although the conventional models are likely of limited use to describe the entire time course data from more than one nitrogen pool, they remain the simplest and quickest way to calculate uptake or regeneration rates from single pool data. The most useful application of the modified Blackburn-Caperon or the Dugdale \& Goering model to time-course data, for example, would probably be to calculate uptake and regeneration rates using successive time points; i.e. not to constrain the model to constant parameters (see Laws 1985).

Our analysis sugggested that a 3-compartment model appears to be more appropriate than the conventionally used 1 or 2-compartment models, particularly in accounting for the incomplete recovery of tracer observed in all experiments. Harrison (1983) and Laws (1984) noted this also in their analyses of Glibert et al.'s (1982) data. The interaction with a third nitrogen pool is further supported by the goodness of fit of ${ }^{15} \mathrm{~N}$ tracer in the $\mathrm{NH}_{4}^{+}$pool to a sum of 3 exponentials model (Berman \& Schoenfield 1956).

Table 3. Comparison between $\mathrm{PON}: \mathrm{NH}_{4}^{+}$ratios measured analytically or predicted from Model 2a, Fig. 8, for Hawaii experiments

\begin{tabular}{|crc|}
\hline Station & Predicted & Measured \\
\hline OS1 & 51.00 & 4.25 \\
OS2 & 1.71 & 2.19 \\
KB1 & 40.00 & 15.20 \\
\hline
\end{tabular}


It is encouraging to note that the same nitrogen exchange models were applicable despite the diversity in environments tested. Model 2a (Fig. 8), which gave the best fit to all the tropical station experiments, predicted an exchange of material between an operationally defined dissolved organic pool and the $\mathrm{NH}_{4}^{+}$pool which was much faster than the exchange between the PON and $\mathrm{NH}_{4}^{+}$pools. Accumulation of the tracer into PON occurred relatively slowly. In these experiments, our analyses suggested that some recycling of ${ }^{15} \mathrm{~N}$ occurred over a $24 \mathrm{~h}$ period. Functional pool sizes estimated from the fitted parameters predicted very small and active $\mathrm{NH}_{4}^{+}$and DON pool sizes.

The Bedford Basin experiment was better described by Model 2c (Fig. 8) which is only a slight modification of the model applied to the Hawaii experiments. The net loss of tracer with time seen in the Bedford Basin experiment might be attributed either to its incorporation into a third pool (DON) which in this case slowly recycles, or perhaps to abiotic adsorption onto the walls of the glass incubation vessel. It has been hypothesized that adsorption onto vessel walls occurs during incubation for orthophosphate uptake experiments, for example (Smith et al, 1985). There is no evidence yet, however, that this occurs with $\mathrm{NH}_{4}^{+}$. Estimates of functional pool sizes could not be obtained for the Bedford Basin experiment. Moreover, no significant recycling of the tracer occurred within the $24 \mathrm{~h}$ incubation period.

It can be legitimately argued that the mechanism of exchange between nitrogen pools presented by Model 2 is probably an oversimplification of a much more complex system (e.g. Lipschultz et al. 1986). Unfortunately, in order to justify a more elaborate model (increased number of pools and of transfer coefficients), one would require a more detailed data set in which more pools were separated and measured. Until this is achieved, one can only speculate as to what these compartments and transfer coefficients represent in nature. For example, in the Hawail experiments, it is possible that a subpool of the particulate material, mainly living microorganisms, is involved in the transfer of the tracer from the $\mathrm{NH}_{4}^{+}$to the DON pool by rapid uptake and recycling of $\mathrm{NH}_{4}^{-}$. Bacteria (heterotrophic and photoautotrophic), for example, may be likely candidates because of their apparent importance in the microplankton communities in these experiments (Renger 1983). Size fractionation of chlorophyll a, ATP and cell counts from the tropical stations indicated that there were 2 major size classes of phototrophs. The 0.4 to $3.0 \mu \mathrm{m}$ and the 5 to $8 \mu \mathrm{m}$ size fractions made up $40 \%$ each of the total chlorophyll a. The small $(0.4$ to $3.0 \mu \mathrm{m})$ size fraction accounted for $48 \%$ of the total ATP, while the larger (5 to $8 \mu \mathrm{m}$ ) size fraction accounted for only $9 \%$. Cell counts indicated that heterotrophic bacteria and phototrophic cyanobacteria were at least 3 and 1 orders of magnitude, respectively, more abundant than other microplankton groups. A rapidly growing bacterial community could probably compete successfuly with phytoplankton for the $\mathrm{NH}_{4}^{+}$(Wheeler \& Kirchman 1986); this type of relationship between microheterotrophs and autotrophs has been recently clearly demonstrated in freshwaters, for phosphorus (Currie \& Kalff 1984a, b). Moreover, Laws et al. (1984) found that at the same tropical stations, $\mathrm{NH}_{4}^{+}$uptake usually exceeded photosynthetic protein synthesis, suggesting that heterotrophs were responsible for a large part of the $\mathrm{NH}_{4}^{+}$uptake. It is possible that our dissolved organic nitrogen' pool represented, at least in part bacteria and small microflagellates (Dugdale \& Wilkerson 1986). The particulate matter for ${ }^{15} \mathrm{~N}$ measurements was collected by filtration onto glass fiber filters. These filters have a nominal pore size of $0.7 \mu \mathrm{m}$ and some passage of micro-organisms through these filters could have occurred (cf. Fergusson et al. 1984). On the other hand, studies by Cuhel et al. (1983) have shown that bacterial passage through glass fiber filters is small. It remains unclear, therefore, whether our third pool was composed of dissolved organic material only or also contained microbes. Although it is not possible to prove that the mechanisms of nitrogen exchange proposed for the tropical stations are correct, the available biological evidence does not disprove our hypothesis.

Recently, Goldman \& Dennett (1985) have shown that cells lacking rigid cell walls may be susceptible to cell breakage and subsequent leakage of the internal pools. They suggested that this fact may explain some of the incomplete tracer recovery often observed in ${ }^{15} \mathrm{~N}$ regeneration experiments (Glibert et al. 1982, Harrison 1983, Laws 1984). The experimental data from the Hawaii station may tend to support this hypothesis since the total recovery of tracer is often lower at the beginning of the experiment than at the end, especially in the case of OS1. This result would be expected if leakage of tracer in the form of low molecular weight nitrogen compound occurred. In later stages of the experiment, the internal pool of low molecular weight nitrogen should be incorporated into proteins and should not be as easily subjected to leakage upon cell bursting especially when filtrations are done with glass fiber filters (Goldman \& Dennett 1985). However, the Bedford Basin experimental data does not support this hypothesis. Furthermore, Laws et al. (1985) presented data on ${ }^{15} \mathrm{~N}$ incorporated into protein which do not support Goldman \& Dennett's (1985) explanation. Fig. 7 of Laws et al. (1985) presents a time-course of the ratio at $\%{ }^{15} \mathrm{~N}$ in protein/total at $\%{ }^{15} \mathrm{~N}$ in PON. The data for ${ }^{15} \mathrm{~N}$ in protein were collected from experiments conducted in parallel with our Hawaii experiments. At all 3 stations, the ratios show an increase with time from as low as $30 \%$ reaching almost $100 \%$ towards the 
end of the incubation 24 h later. If a significant leakage of the internal unassimilated nitrogen occurred, one would expect the ratio of ${ }^{15} \mathrm{~N}$ in protein $/{ }^{15} \mathrm{~N}$ in PON to be higher and relatively constant. Since both measurements of at\% ${ }^{15} \mathrm{~N}$ in proteins and at\% ${ }^{15} \mathrm{~N}$ in $\mathrm{PON}$ require filtration onto $\mathrm{GF} / \mathrm{F}$ filters, cell breakage, if it occurred, should have affected both samples equally. The fact that TCA-soluble material can still be extracted after the initial filtration and rinsing steps suggests that cell leakage was not a significant problem in these experiments and cannot explain satisfactorily the patterns of tracer recovery obtained in our results.

Strong arguments can be made against attempts to model $24 \mathrm{~h}$ time-course experiments. For example, there may be a gradual species selection during the course of the incubation that could significantly affect the experimental outcome. However, direct cell counts (L. Haas unpubl. data) indicated that there was no general pattern in the species composition of the plankton during the course of an experiment. In the OS1 experiment, there was a net increase in all the groups of organisms present. On the other hand, mortality of heterotrophic and autotrophic flagellates was observed in the OS2 experiment. In all the experiments, bacteria and cyanobacteria were abundant throughout the incubation.

Alternatively, diurnal variations may be too pronounced to allow description of the data with a simple model (Pages \& Lemasson 1982). In our case, significant changes that could be attributed to a diurnal light cycle could be detected only at the OS1 station. This was different from parallel phosphorus time-courses (Smith et al. 1985) in which a dawn surge in phosphorus uptake was often observed.

\section{Comparison with modified Blackburn-Caperon model}

Table 4 shows a comparison of regeneration rates calculated from Model 2a (Fig. 8) and the modified Blackburn-Caperon model. Since rates calculated from the modified Blackburn-Caperon model vary with incubation time (Harrison \& Harris 1986), the range of the values calculated throughout the time-course have been included. The values derived from Model $2 \mathrm{a}$ are close to or fall within the range of these derived from the modified Blackburn-Caperon model, indicating some agreement between the estimates. It is difficult, however, to compare the results obtained from these 2 approaches since, in our analysis, it was found that (1) measured and predicted pool sizes did not agree, and (2) the $\mathrm{NH}_{4}^{+}$and DON pools exchanged rapidly with each other. The rapid exchange occurring between DON and $\mathrm{NH}_{4}^{+}$did not greatly affect the calculation of uptake rate by PON (or, indirectly, growth rate calculations) which contrasts with the results found by Smith et al. (1985) for phosphorus cycling. Several improvements in the calculation of uptake rates have been introduced recently (Glibert et al, 1982, Laws 1984) involving the use of time averages of the function describing the change in at ${ }^{15} \mathrm{~N}$ in the $\mathrm{NH}_{4}^{+}$pool. Our results indicate a systematic lack of fit of both a single exponential and the Blackburn-Caperon equations. In our experiments, a time average of a sum of 3 exponentials model would give a better estimate of the mean at $\%{ }^{15} \mathrm{~N}$ ratio in the $\mathrm{NH}_{4}^{+}$pool.

The data also indicate that end-point measurements, whether from short or long incubations, can lead to bias in calculated uptake rates. Our results suggest that short term time-courses of the order of minutes (e.g. Goldman et al. 1981) can also be misleading. For example, in the OS1 experiment, half of the ${ }^{15} \mathrm{~N}$ tracer introduced in the $\mathrm{NH}_{4}^{+}$pool was not recovered in either the $\mathrm{NH}_{4}^{+}$or the PON pools within a few minutes following tracer addition. The lost tracer gradually reappeared in these 2 pools towards the end of the incubation, $24 \mathrm{~h}$ later.

The model which seemed to best describe our data is different from the modified Blackburn-Caperon model often used in ${ }^{15} \mathrm{~N}$ cycling studies. Recent models of phosphorus and carbon cycling also incorporate a dissolved organic pool. However, there exist differences in the behaviour of tracer kinetics among planktonic communities and among types of nutrients (phosphorus, nitrogen, carbon). It may prove difficult to make accurate estimates of cycling rates when one does not know the cycling mechanism. The approach of compartmental analysis of time-course data provides a means of testing several possible tracer exchange pathways between a number of compartments. It would be desirable in future experiments to perform detailed timecourses in several different environments in order to examine whether there exist any common patterns of nitrogen cycling. Furthermore, attempts should be made to obtain mass balances of the tracer isotope and to discriminate between any 'sub-pools' within the particulate and dissolved organic matter pools.

Table 4. Comparison of $\mathrm{NH}_{4}^{+}$regeneration rates from PON measured from the fit of Model $2 a$ i.e. $(L[2,1] \times$ PON concentration) and those measured from the conventional BlackburnCaperon model, for the tropical stations OS1, OS2 and KB1

\begin{tabular}{|cccc|}
\hline Station & $\begin{array}{c}\text { Model 2a, Fig. 8 } \\
\text { (nmoles } \mathrm{l}^{-1} \mathrm{~h}^{-1} \text { ) }\end{array}$ & $\begin{array}{c}\text { Blackburn-Caperon } \\
\text { (nmoles } \mathrm{l}^{-1} \mathrm{~h}^{-1} \text { ) } \\
\text { Minimum }\end{array}$ & Maximum \\
\hline OS1 & 2.38 & 9 & 46 \\
OS2 & 34.3 & 8 & 95 \\
KB1 & 143.4 & 20 & 117 \\
\hline
\end{tabular}


Acknowledgements. We thank Dr Ralph Smith for help in the early formulation of this problem and for critically reading this manuscript. We are grateful to Dr L. Haas for the use of unpublished data and to Dr E. A. Laws for critical comments on an earlier draft of the manuscript. Support for this work was provided by funds from the NSF coordination and logistics grant NSF oCE 81-20773 for the PRPOOS program (R. W. Eppley). J. L. R. was supported by the National Science and Engineering Research Council, Canada lawarded to W. G. H.).

\section{LITERATURE CITED}

Anderson, D. E. (1983). Compartmental modelling and tracer kinetics. Lecture notes in biomathematics, Vol. VII. Springer-Verlag, Berlin

Berman, H., Weiss, H. F. (1978). SAAM Manual. U. S. Dept Health, Education and Welfare, Publication NIH-78-180

Berman, H., Schoenfeld, R. (1956). Invariants in experimental data on linear kinetics and the formulation of models. Appl. Phys. 27: 1361-1370

Blackburn, T. H. (1979). Method for measuring rates of $\mathrm{NH}_{4}^{+}$ turnover in anoxic marine sediments, using a ${ }^{15} \mathrm{~N}-\mathrm{NH}_{4}^{+}$ dilution technique. Appl. environ. Microbiol. 37: 760-765

Caperon, J., Schell, D., Hirota, J., Laws, E. (1979). Ammonium excretion rates in Kaneohe Bay, Hawaii, measured by a ${ }^{15} \mathrm{~N}$ isotope dilution technique. Mar. Biol. 54: 33-40

Cuhel, R. L., Jannach, H. W., Taylor, C. D. (1983). Microbial growth and macromolecular synthesis in the northwestern Atlantic Ocean. Limnol. Oceanogr. 28: 1-18

Currie, D. J., Kalff, J. (1984a). A comparison of the abilities of freshwater algae and bacteria to acquire and retain phosphorus. Limnol. Oceanogr. 29: 298-310

Currie, D. J., Kalff, J. (1984b). The relative importance of bacterioplankton and phytoplankton in phosphorus uptake in freshwater. Limnol. Oceanogr. 29: 311-321

Dring, M. J., Jewson, D. H. (1982). What does ${ }^{14} \mathrm{C}$ uptake by phytoplankton really measure? A theoretical modelling approach. Proc. R. Soc. Lond. (B) 214: 351-368

Dugdale, R. C., Goering, J. J. (1967). Uptake of new and regenerated forms of nitrogen in primary productivity. Limnol. Oceanogr. 12: 196-206

Dugdale, R. C., Wilkerson, F. P. (1986). The use of ${ }^{15} \mathrm{~N}$ to measure nitrogen uptake in eutrophic oceans; experimental considerations. Limnol. Oceanogr. 31: 673-689

Eppley, R. W. (1982). The PRPOOS program: a study of plankton rate processes in oligotrophic oceans. EOS Trans. Am. Ecophys. Union 163: 522

Ferguson, R. L., Buckley, E. N., Palumbo, A. V (1984). Response of marine bacterioplankton to differential filtration and confinement Applied environ. Microbiol. 47: $49-55$

Fitzwater, S. E., Knauer, G. A., Martin, J. H. (1982). Metal contamination and its effect on primary production measurements. Limnol. Oceanogr. 27: 544-551

Garside, C., Glibert, P. M. (1984). Computer modelling of ${ }^{15} \mathrm{~N}$ uptake and remineralization experiments. Limnol. Oceanogr 29: 199-203

Glibert, P. M., Lipschultz, F., McCarthy, J. J., Altabet, M. A. (1982). Isotope dilution models of uptake and remineralization of ammonium by marine plankton. Limnol. Oceanogr. 27: 639-650

Goldman, J. C., Dennett, M. R. (1985). Susceptibility of some marine phytoplankton species to cell breakage during filtration and post filtration rinsing. J. exp. Mar Biol. Ecol. 86: $47-58$
Goldman, J. C. Taylor, C. D., Glibert, P. M. (1981). Nonlinear time-course uptake of carbon and ammonium by marine phytoplankton. Mar. Ecol. Prog. Ser. 6: 137-148

Harrison, W G. (1978). Experimental measurements of nitrogen remineralization in coastal waters. Limnol. Oceanogr. 23: $684-694$

Harrison, W G. (1983). Uptake and recycling of soluble reactive phosphorus by marine microplankton. Mar. Ecol. Prog. Ser. 10: 127-135

Harrison, W. G., Harris, L. R. (1986). Isotope-dilution and its effects on measurements in nitrogen and phosphorus uptake by oceanic microplankton. Mar. Ecol. Prog. Ser. 27: 253-261

Jacquez, J. A. (1972). Compartmental analysis in biology and medicine. Elsevier Publishing Company, New York

LaRoche, J. (1981). Ammonium regeneration: its contribution to phytoplankton nitrogen requirements in a eutrophic environment. $\mathrm{M}$. Sc. thesis, Dalhousie University

LaRoche, J. (1983). Ammonium regeneration: its contribution to phytoplankton nitrogen requirements in a eutrophic environment. Mar. Biol. 75: 231-240

Laws, E. A. (1984). Isotope dilution models and the mystery of the vanishing ${ }^{15} \mathrm{~N}$. Limnol. Oceanogr. 29: 379-385

Laws, E. A. (1985). Analytical model of $\mathrm{NH}^{+}$uptake and regeneration experiments. Limnol. Oceanogr. 30: $1340-1350$

Laws, E. A., Harrison, W. G., Ditullio, G. R. (1985). A comparison of nitrogen assimilation rates based on ${ }^{15} \mathrm{~N}$ uptake and autotrophic protein synthesis. Deep Sea Res. 32: 85-95

Laws, E. A., Redalge, D. G., Haas, L. W., Bienfang, P. K., Eppley, R. W., Harrison, W. G., Karl, D. M., Marra, J, (1984). High phytoplankton growth and production rates in oligotrophic Hawaiian coastal waters. Limnol. Oceanogr. 29: 1161-1169

Lean, D. R. (1973). Movements of phosphorus between its biologically important forms in lake water. J. Fish. Res. Bd Can. 30: 1525-1536

Lipschultz, F., Wofsy, S. C., Fox, L. E. (1986). Nitrogen metabolism of the eutrophic Delaware River ecosystem. Limnol. Oceanogr. 31: 701-716

Nie, N. H., Hull, C. H., Jenkins, J. G., Steimbrenner, K., Bent, D. H. (1975). SPSS: statistical package for the social sciences. 2nd edn. McGraw-Hill Book Company

Paasche, E., Kristiansen, S. (1982). Ammonium regeneration by microplankton in the Oslofjord. Mar. Biol. 69: 55-63

Pages, J., Lemasson, L. (1982). Essai de modelization de l'assimilation de ${ }^{32} \mathrm{P}$ par le phytoplankton. Oceanogr. Trop. $17 \cdot 145-154$

Renger, E. H. (ed.) (1983). PRPOOS Program in Hawaii, August-September, 1982 (Plankton Rate Processes in Oligotrophic Oceans) Data Report. IMR Reference No. 83-5. NSF. Univ, of California, San Diego

Rice, I R. (1953). Phosphorus exchange in marine phytoplankton. Fish. Bull. Fish. Widl. Serv. U. S. 54: 77-89

Rigler, F. H. (1956). A tracer study of the phosphorus cycle in lake water Ecology 37(3): 550-562

Riggs, D. S. (1972). The mathematical approach to physiological problems. The M.I.T Press. Cambridge, Massachusetts

Sheppard, C. W. (1962). Basic principles of the tracer method. John Wiley and Sons, New York

Smith, D. F. (1974). Quantitative analysis of the functional relationships existing between ecosystem components. II Analysis of non-linear relationships. Oecologia (Berl.) 16 $107-117$

Smith, R. E. H. (1982). The estimation of phytoplankton production and excretion by ${ }^{14} \mathrm{C}$. Mar. Biol. Lett. 3: 325-334

Smith, R. E. H., Harrison, W. G., Harris, L. (1985). Phosphorus 
exchange in marine microplankton communities near Hawaij. Mar. Biol. 86: 75-84

Smith, R. E. H., Platt, T. (1984). Carbon exchange and ${ }^{14} \mathrm{C}$ tracer methods in a nitrogen-limited diatom, Thalassiosira pseudonana. Mar. Ecol. Prog. Ser. 16: 75-87

Steeman-Nielsen, E. (1952). The use of radioactive carbon $\left({ }^{14} \mathrm{C}\right)$ for measuring organic production in the sea. J. Cons. perm. int. Explor. Mer 18: 117-140

Taft, J. L., Taylor, W. R., McCarthy, J. J. (1975). Uptake and release of phosphorus by phytoplankton in the Chesapeake Bay Estuary, USA. Mar. Biol. 33: 21-32

Wheeler, P. A., Kirchman, D. L. (1986). Utilization of inorganic and organic nitrogen by bacteria in marine systems. Limnol. Oceanogr. 31: 998-1009

Wiebe, W. J., Smith, D. F. (1977). Direct measurement of dissolved organic carbon released by phytoplankton and incorporated by microheterotrophs. Mar. Biol. 42: 213-223

This article was submitted to the editor; it was accepted for printing on February 25, 1987 